\title{
Commentary
}

\section{An update of the KIDMED questionnaire, a Mediterranean Diet Quality Index in children and adolescents}

\author{
Cesare Altavilla ${ }^{1}$ and Pablo Caballero-Pérez $z^{2, *}$ \\ ${ }^{1}$ Foods Analysis and Nutrition Group, University of Alicante, Alicante, Spain: ${ }^{2}$ Department of Community Nursing, \\ Preventive Medicine, Public Health and History of Science, University of Alicante, Campus de San Vicente del Raspeig, \\ 03540 San Vicente del Raspeig (Alicante), Spain
}

Submitted 14 May 2018: Final revision received 28 January 2019: Accepted 22 February 2019: First published online 31 May 2019

\begin{abstract}
Objective: The KIDMED questionnaire was published in 2004 to evaluate adherence to the Mediterranean diet (MD) in children and adolescents. In the last 14 years, several respected official dietetics and health organizations have recommended appropriate dietary habits, including eating whole grains and consuming whole fruit rather than fruit juice. We propose an update of the KIDMED questionnaire.

Design: Based on the scientific evidence, the present commentary suggests some changes to the KIDMED questionnaire.

Results: We suggest deleting 'or fruit juice' from the first question of the questionnaire, rewording the question as 'Takes a fruit every day', and assigning a positive value of +1 . We suggest adding 'whole-grain' to the eighth question of the questionnaire, rewording the question as 'Consumes whole-grain pasta or whole-grain rice almost every day ( 5 or more times per week)', and assigning a positive value of +1 . Further, we propose to add 'whole cereals or whole grains' to the ninth question of the questionnaire, reword the question as 'Has whole cereals or whole grains (whole-meal bread, etc.) for breakfast', and assign a positive value of +1 .

Conclusions: The present commentary examines some signs of a paradigm shift about fruit juice and whole grains after the development of the KIDMED questionnaire. The changes are of paramount importance in order to make the questionnaire an updated tool to evaluate adherence to the MD.
\end{abstract}

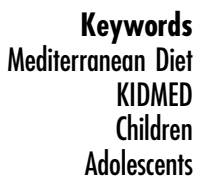

The KIDMED questionnaire was published in 2004 in Public Health Nutrition ${ }^{(1)}$. The KIDMED questionnaire has been used for more than a decade by researchers, nutritionists and educators to evaluate adherence to the Mediterranean diet (MD) in children and adolescents. A recent study has shown that the KIDMED questionnaire is the most widely used scoring system to assess adherence to the MD in children and adolescents ${ }^{(2)}$. Several studies have been carried out in Spain ${ }^{(3-6)}$ and others in the Mediterranean area ${ }^{(7-9)}$. Few data are available for non-Mediterranean countries $^{(10,11)}$. Obesity is increasing in Greece, which topped the Organisation for Economic Co-operation and Development's childhood obesity league in 2014, followed by Italy ${ }^{(12)}$. The last few decades have seen considerable changes in the dietary habits of the Mediterranean population, especially in children and adolescents. High energy intake and the massive consumption of high-sugar foods (such as soft drinks, sweets, bakery products) and other refined or ultra-processed foods have impacted upon nutritional habits ${ }^{(13,14)}$. These foods have replaced traditional and local Mediterranean foods. The decreased adherence to the MD probably has detrimental health effects for the Mediterranean population ${ }^{(15)}$. The repeated inclusion of certain foods such as fruit juice, refined cereals or refined grains in the MD may have negative effects on health ${ }^{(16-18)}$. We consider the larger issue of scientific responsibility for improving and updating a common tool used to assess adherence to the MD. The authors of the present 
commentary used the KIDMED questionnaire for our studies; as a result of our studies, we propose a critical appraisal of the KIDMED questionnaire.

\section{Discussion and modifications}

\section{The first question}

The first question assigns a positive value of +1 if a child or an adolescent takes fruit or fruit juice every day. This question highlights an equivalence between fruit and fruit juice. Historically, fruit juice was marketed as a healthy drink and it was recommended by paediatricians. Recent studies advance the call for some update in the first question to better reflect current research. Our approach to the change proposed in the first question is to consider as healthy MD only the daily intake of fruit. We should not consider fruit juice as a staple food with a daily intake. Several studies have declared that daily intake of fruit juice is not recommended $^{(14,16,19)}$. Fruit juice intake was negatively associated with the prevention of type 2 diabetes, whereas an increase in whole fruit consumption was associated with a lower hazard for diabetes ${ }^{(20,21)}$. Any sugar-sweetened drinks, fruit drinks, sports/energy drinks, sweetened iced teas or homemade beverages which contain at least $210 \mathrm{~kJ}$ (50 kcal) per $240 \mathrm{ml}$ ( 8 US fluid ounce) serving have been considered sweetened sugar beverages, but $100 \%$ fruit juice was excluded ${ }^{(14)}$. Unfortunately, a single 240 $\mathrm{ml}$ glass of $100 \%$ fresh orange juice contains more than $210 \mathrm{~kJ}^{(13)}$. Whole fruit has a different macronutrient composition, including fewer kilojoules from sugar, compared with fruit juice or any other fruit beverages ${ }^{(16)}$. The sales of soft beverages, including juice, soft drinks, energy drinks, coffee, sweetened tea and any other combination, have increased and are expected to continue growing in the next few years. The intake of sugar-sweetened beverages and fruit juices has become a major source of fluid intake in the USA ${ }^{(22)}$ and it is possible that the same will occur in Europe in the next few years. Generally, children and adolescents are the highest consumers of fruit juice and juice drinks. Children and adolescents do not know the differences between these beverages because juice is supposed to be $100 \%$ fruit or vegetables, and commonly they drink juice regardless if it is fruit juice, fruit drinks with about $5-15 \%$ of fruit juice, juice with milk, teas with fruit or any other combinations. There is emerging evidence that the intake of juices may contribute to obesity ${ }^{(13,14,16,23)}$. There is no equivalence between fruit and fruit juice. The physiological responses of the human body to solid and liquid fruit are different ${ }^{(24)}$. In the last decade several respected official dietetics and health organizations have recommended appropriate dietary habits, including consuming whole fruit rather than fruit juice ${ }^{(17,25,26)}$. Having a fruit every day is definitively a Mediterranean eating and healthy habit. The WHO, American Cancer Society and other European dietary guidelines suggest the consumption of at least $4-5$ servings of fruit and vegetables per day ${ }^{(27,28)}$. The US Department of Agriculture's MyPlate guideline has recommended to fill a quarter of the plate with coloured fruits ${ }^{(29)}$. An increase of fruit intake ${ }^{(30)}$ and water intake $^{(31)}$ instead of fruit juice has some benefits on obesity and weight loss, especially among children and adolescents. We support the inclusion of high amounts of fruit in the diet of children and adolescents to improve a healthy MD. Therefore, we propose to the authors to delete 'or fruit juice' from the first question of the KIDMED questionnaire and reword the question as: 'Takes a fruit every day' and assign a positive value of +1 (see Table 1). The new first question is also correctly related to the second question of the KIDMED questionnaire.

\section{The eighth and ninth questions: whole-grain foods}

The core of our critical appraisal for the eighth and the ninth question is similar. There is extensive scientific literature on the benefits of the intake of whole-grain foods ${ }^{(32-34)}$. Based on the latest scientific literature, our proposed approach to the change the questionnaire is to consider as healthy MD only the intake of whole cereals and whole grains. Refined cereals or grains and derived foods should not be included in the healthy MD as staple foods with daily intake. In the Mediterranean countries there is a high intake of refined cereals and grains for breakfast and this could be considered partially a Mediterranean eating habit. Furthermore, high intake of refined cereals and grains cannot be considered a healthy habit. Scientific evidence indicates that refined carbohydrates, sugar, whole grains and dietary fibre play important roles in diabetes, obesity, CVD ${ }^{(35)}$ and other related chronic diseases ${ }^{(36)}$. Our suggestion to the authors is to assign a positive value of +1 in the eighth and ninth questions if a child or adolescent consumes whole-grain foods.

\section{The eighth question}

The eighth question assigns a positive value of +1 if a child or adolescent takes pasta or rice almost every day ( 5 or more times per week). Research on the public health impact of refined carbohydrates and of whole cereals is of great importance in the context of the obesity epidemic and some other related chronic diseases. Since 2011 the Healthy Eating Plate of Harvard University has indicated that most carbohydrate intake should come from whole grains rather than refined grains ${ }^{(25)}$. The recent update of the report of World Cancer Research Fund and the American Institute for Cancer Research has recommended to make whole grains part of the usual daily diet ${ }^{(37)}$. It has been estimated that the glycaemic index of white rice is higher than that of brown rice ${ }^{(38,39)}$. Brown rice has more fibre and more vitamins than white rice. Substitution of whole grains, including brown rice, for white rice may facilitate the prevention of type 2 diabetes and help with 
Table 1 Update of the KIDMED questionnaire to assess quality of the Mediterranean diet in children and adolescents

\begin{tabular}{ll}
\hline Score & Criterion \\
\hline+1 & Takes a fruit every day \\
+1 & Has a second fruit every day \\
+1 & Has fresh or cooked vegetables regularly once per day \\
+1 & Has fresh or cooked vegetables more than once per day \\
+1 & Consumes fish regularly (at least $2-3$ times per week) \\
-1 & Goes to a fast-food (hamburger) restaurant more than once per week \\
+1 & Likes pulses and eats them more than once per week \\
+1 & Consumes whole-grain pasta or whole-grain rice almost every day (5 or more times per week) \\
+1 & Has whole cereals or whole-grains (whole-meal bread, etc.) for breakfast \\
+1 & Consumes nuts regularly (at least $2-3$ times per week) \\
+1 & Uses olive oil at home \\
-1 & Skips breakfast \\
+1 & Has a dairy product for breakfast (yoghurt, milk, etc.) \\
-1 & Has commercially baked goods or pastries for breakfast \\
+1 & Takes two yoghurts and/or some cheese (40 g) daily \\
-1 & Takes sweets and candy several times every day \\
\hline KIDMED, Mediterranean Diet Quality Index in children and adolescents. \\
Value of the KIDMED score: $\leq 3$, very-low-quality diet; $4-7$, need to improve the food pattern to adjust it to the Mediterranean one; $\geq 8$, \\
optimal Mediterranean diet.
\end{tabular}

other non-communicable diseases such as obesity and $\mathrm{CVD}^{(35)}$. Therefore, we suggest to the authors to add 'whole-grain' to the eighth question of the questionnaire and reword the question as: 'Consumes whole-grain pasta or whole-grain rice almost every day ( 5 or more times per week)' and assign a positive value of +1 (see Table 1).

\section{The ninth question}

The ninth question assigns a positive value of +1 if a child or an adolescent has cereals or grains (bread, etc.) for breakfast. First of all, it is probable that children and adolescents can misunderstand the term 'cereals for breakfast' as ready-to-eat cereals. The intake of ready-to-eat cereals at breakfast time has increased over the last decades ${ }^{(40,41)}$. Actually, ready-to-eat cereals are one of the most frequent breakfasts among children and adolescents ${ }^{(42)}$. Ready-toeat cereals are not a Mediterranean food and most important they are non-compliant with the European nutrient profile model, especially regarding sugar content ${ }^{(42,43)}$. If the cereals or grains are whole grains, the nutritional value will be higher compared with refined ones. Whole grains generally produce a lower postprandial glucose response ${ }^{(44)}$. The protective mechanism of whole grains is explained mainly by dietary fibre, resistant starch and oligosaccharides. Whole grains contain vitamins, minerals, phenolic compounds and phyto-oestrogens that have been related to protecting against cancer $^{(45)}$. Protection against the risk of cancers related to hormones and pancreatic cancer has been associated with the regular consumption of whole-grain cereals ${ }^{(46)}$. Therefore, we suggest to the authors to add 'whole cereals or whole grains' to the ninth question of the KIDMED questionnaire and reword the question as: 'Has whole cereals or whole grains (whole-meal bread, etc.) for breakfast' and assign a positive value of +1 (see Table 1 ).

\section{Conclusions}

Recent studies advance the call for some update in the KIDMED questionnaire, to better reflect current guidelines and research, as well as the basic principles of the MD. We propose an update of the first, eighth and ninth questions of the KIDMED questionnaire. The modifications about fruit juice and whole-grain foods make the questionnaire a better tool to evaluate the adherence to the MD. Some implications for practice and research are possible. The next question could be: is it possible that these modifications can change the mean adherence score to the MD?

\section{Acknowledgements}

Acknowledgements: Anthony Sweeney and Isabel Rodríguez of the Schoola Institute of Alicante have collaborated with language assistance. Financial support: This research received no specific grant from any funding agency in the public, commercial or not-for-profit sectors. Conflict of interest: None of the authors has any conflicts of interest or financial ties to disclose. Authorship: C.A. and P.C.-P. are authors of this commentary, both argued the discussed issues, designed the new proposal and wrote the manuscript. Ethics of human subject participation: Not applicable.

Author ORCIDs. (10) Cesare Altavilla, 0000-0002-74154139. Pablo Caballero-Pérez, 0000-0002-1234-2150.

\section{References}

1. Serra-Majem L, Ribas L, Ngo J et al. (2004) Food, youth and the Mediterranean diet in Spain. Development of KIDMED, 
Mediterranean Diet Quality Index in children and adolescents. Public Health Nutr 7, 931-935.

2. Iaccarino Idelson P, Scalfi L \& Valerio G (2017) Adherence to the Mediterranean diet in children and adolescents: a systematic review. Nutr Metab Cardiovasc Dis 27, 283-299.

3. Rubio-Arias JÁ, Ramos Campo DJ, Ruiloba Nuñez JM et al. (2015) Adhesión a la dieta mediterránea y rendimiento deportivo en un grupo de mujeres deportistas de élite de fútbol sala (Adherence to a Mediterranean diet and sport performance in elite female athletes futsal population). Nutr Hosp 31, 2276-2282.

4. Egeda Manzanera JM \& Rodrigo Vega M (2014) Adherencia a la Dieta Mediterránea en futuras maestras (Adherence to the Mediterranean diet of future teachers). Nutr Hosp $\mathbf{3 0}$, 343-350.

5. Alacid F, Vaquero-Cristóbal R, Sánchez-Pato A et al. (2014) Adhesión a la dieta mediterránea y relación con los parámetros antropométricos de mujeres jóvenes kayakistas (Habit based consumptions in the Mediterranean diet and the relationship with anthropometric parameters in young female kayakers). Nutr Hosp 29, 121-127.

6. Navarro-González I, López-Nicolás R, Rodríguez-Tadeo A et al. (2014) Adherence to the Mediterranean diet by nursing students of Murcia (Spain). Nutr Hosp 30, 165-172.

7. Mistretta A, Marventano S, Antoci M et al. (2017) Mediterranean diet adherence and body composition among Southern Italian adolescents. Obes Res Clin Pract 11, 215-226.

8. Sahingoz SA \& Sanlier N (2011) Compliance with Mediterranean Diet Quality Index (KIDMED) and nutrition knowledge levels in adolescents. A case study from Turkey. Appetite 57, 272-277.

9. Papadaki S \& Mavrikaki E (2015) Greek adolescents and the Mediterranean diet: factors affecting quality and adherence. Nutrition 31, 345-349.

10. Muros JJ, Cofre-Bolados C, Arriscado D et al. (2017) Mediterranean diet adherence is associated with lifestyle, physical fitness, and mental wellness among 10 -y-olds in Chile. Nutrition 35, 87-92.

11. Fernando Rodríguez R, Ximen Palma L, Ángela Romo B et al. (2013) Hábitos alimentarios, actividad física y nivel socioeconómico en estudiantes universitarios de Chile (Eating habits, physical activity and socioeconomic level in university students of Chile). Nutr Hosp 28, 447-455.

12. Organisation for Economic Co-operation and Development (2014) Obesity Update, June 2014. Paris: OECD Directorate for Employment, Labour and Social Affairs.

13. Singh GM, Micha R, Khatibzadeh S et al. (2015) Estimated global, regional, and national disease burdens related to sugar-sweetened beverage consumption in 2010. Circulation 132, 639-666.

14. Singh GM, Micha R, Khatibzadeh S et al. (2015) Global, regional, and national consumption of sugar-sweetened beverages, fruit juices, and milk: a systematic assessment of beverage intake in 187 countries. PLoS One 10, e0124845.

15. da Silva R, Bach-Faig A, Raidó Quintana B et al. (2009) Worldwide variation of adherence to the Mediterranean diet, in 1961-1965 and 2000-2003. Public Health Nutr 12, 1676-1684.

16. Wojcicki JM \& Heyman MB (2012) Reducing childhood obesity by eliminating $100 \%$ fruit juice. Am J Public Health 102, 1630-1633.

17. Heyman MB \& Abrams SA (2017) Fruit juice in infants, children, and adolescents: current recommendations. Pediatrics 139, e20170967.

18. Issa C, Darmon N, Salameh P et al. (2011) A Mediterranean diet pattern with low consumption of liquid sweets and refined cereals is negatively associated with adiposity in adults from rural Lebanon. Int J Obes (Lond) 35, 251-258.
19. Popkin BM, Armstrong LE, Bray GM et al. (2006) A new proposed guidance system for beverage consumption in the United States. Am J Clin Nutr 83, 529-542.

20. Bazzano LA, Li TY, Joshipura KJ et al. (2008) Intake of fruit, vegetables, and fruit juices and risk of diabetes in women. Diabetes Care 31, 1311-1317.

21. Imamura F, O'Connor L, Ye Z et al. (2016) Consumption of sugar sweetened beverages, artificially sweetened beverages, and fruit juice and incidence of type 2 diabetes: systematic review, meta-analysis, and estimation of population attributable fraction. Br J Sports Med 50, 496-504.

22. Bleich SN, Wang YC, Wang Y et al. (2009) Increasing consumption of sugar-sweetened beverages among US adults: 1988-1994 to 1999-2004. Am JClin Nutr 89, 372-381.

23. Shefferly A, Scharf RJ \& DeBoer MD (2016) Longitudinal evaluation of $100 \%$ fruit juice consumption on BMI status in 2-5-year-old children. Pediatr Obes 11, 221-227.

24. Flood-Obbagy JE \& Rolls BJ (2009) The effect of fruit in different forms on energy intake and satiety at a meal. Appetite $\mathbf{5 2}$, 416-422.

25. Harvard T.H. Chan School of Public Health (2011) The Nutrition Source | Healthy Eating Plate. https://www. hsph.harvard.edu/nutritionsource/healthy-eating-plate/ (accessed April 2019).

26. World Health Organization (2015) Guideline. Sugars Intake for Adults and Children. Geneva: WHO.

27. Food and Agriculture Organization of the United Nations (2011) Food-based dietary guidelines - France: The French National Nutrition and Health Program's dietary guidelines. http://www.fao.org/nutrition/education/food-based-dietaryguidelines/regions/countries/france/en/ (accessed April 2019).

28. World Health Organization (2003) Food Based Dietary Guidelines in the WHO European Region. Geneva: WHO.

29. US Department of Agriculture (2019) Choose MyPlate. https://www.choosemyplate.gov/ (accessed April 2019).

30. Sharma SP, Chung HJ, Kim HJ et al. (2016) Paradoxical effects of fruit on obesity. Nutrients $\mathbf{8}$, E633.

31. Fresán U, Gea A, Bes-Rastrollo M et al. (2016) Substitution models of water for other beverages, and the incidence of obesity and weight gain in the SUN cohort. Nutrients $\mathbf{8}$, E688.

32. Aune D, Keum N, Giovannucci E et al. (2016) Whole grain consumption and risk of cardiovascular disease, cancer, and all cause and cause specific mortality: systematic review and dose-response meta-analysis of prospective studies. BMJ 353, i2716.

33. Zong G, Gao A, Hu FB et al. (2016) Whole grain intake and mortality from all causes, cardiovascular disease, and cancer: a meta-analysis of prospective cohort studies. Circulation 133, 2370-2380.

34. Mozaffarian RS, Lee RM, Kennedy MA et al. (2013) Identifying whole grain foods: a comparison of different approaches for selecting more healthful whole grain products. Public Health Nutr 16, 2255-2264.

35. Temple NJ (2018) Fat, sugar, whole grains and heart disease: 50 years of confusion. Nutrients 10, E39.

36. Chen J-P, Chen G-C, Wang X-P et al. (2017) Dietary fiber and metabolic syndrome: a meta-analysis and review of related mechanisms. Nutrients 10, E24.

37. World Cancer Research Fund \& American Institute for Cancer Research (2018) Cancer Prevention Recommendations. Diet, Nutrition, Physical Activity and Cancer: A Global Perspective. Continuous Update Project Expert Report. Washington, DC: WCRF International.

38. Kaur B, Ranawana V \& Henry J (2016) The glycemic index of rice and rice products: a review, and table of GI values. Crit Rev Food Sci Nutr 56, 215-236. 
39. Shobana S, Kokila A, Lakshmipriya N et al. (2012) Glycaemic index of three Indian rice varieties. Int J Food Sci Nutr $\mathbf{6 3}$ 178-183.

40. Kafatos A, Linardakis M, Bertsias G et al. (2005) Consumption of ready-to-eat cereals in relation to health and diet indicators among school adolescents in Crete, Greece. Ann Nutr Metab 49, 165-172.

41. Mullan BA \& Singh M (2010) A systematic review of the quality, content, and context of breakfast consumption. Nutr Food Sci 40, 81-114.

42. Rito AI, Dinis A, Rascôa C et al. (2018) Improving breakfast patterns of Portuguese children - an evaluation of ready-toeat cereals according to the European nutrient profile model. Eur J Clin Nutr 73, 465-473.
43. DIABETES UK (2019) Breakfast cereals. https://www. diabetes.org.uk/guide-to-diabetes/enjoy-food/eating-withdiabetes/diabetes-food-myths/breakfast-cereals (accessed April 2019)

44. Marventano S, Vetrani C, Vitale M et al. (2017) Whole grain intake and glycaemic control in healthy subjects: a systematic review and meta-analysis of randomized controlled trials. Nutrients 9, E769.

45. Slavin J (2003) Why whole grains are protective: biological mechanisms. Proc Nutr Soc 62, 129-134.

46. Gil A, Ortega RM \& Maldonado J (2011) Wholegrain cereals and bread: a duet of the Mediterranean diet for the prevention of chronic diseases. Public Health Nutr 14, 2316-2322. 